\title{
DECISION MAKING IN THE ASSIGNMENT PROCESS BY USING THE HUNGARIAN ALGORITHM WITH OWA OPERATORS
}

\author{
Emili VIZUETE-LUCIANO ${ }^{\mathrm{a}}$, José M. MERIGÓb, Anna M. GIL-LAFUENTEa ${ }^{\mathrm{a}}$, \\ Sefa BORIA-REVERTER ${ }^{\mathrm{a}}$ \\ ${ }^{a}$ Department of Business Administration, University of Barcelona,bAv. Diagonal 690, \\ 08034 Barcelona, Spain \\ ${ }^{b}$ Manchester Business School, University of Manchester, Booth Street West, M15 6PB, \\ Manchester, UK
}

Received 5 December 2012; accepted 8 December 2013

\begin{abstract}
Assignment processes permit to coordinate two set of variables so each variable of the first set is connected to another variable of the second set. This paper develops a new assignment algorithm by using a wide range of aggregation operators in the Hungarian algorithm. A new process based on the use of the ordered weighted averaging distance (OWAD) operator and the induced OWAD (IOWAD) operator in the Hungarian algorithm is introduced. We refer to it as the Hungarian algorithm with the OWAD operator (HAOWAD) and the Hungarian algorithm with the IOWAD operator (HAIOWAD). The main advantage of this approach is that we can provide a parameterized family of aggregation operators between the minimum and the maximum. Thus, the information can be represented in a more complete way. Furthermore, we also present a general framework by using generalized and quasi-arithmetic means. Therefore, we can consider a wide range of particular cases including the Euclidean and the Minkowski distance. The paper ends with a practical application of the new approach in a financial decision making problem regarding the assignment of investments.
\end{abstract}

Keywords: uncertainty modelling, OWA operators, Hungarian algorithm, assignment theory, distance measure.

JEL Classification: C43, C44, D81, G11.

\section{Introduction}

In real life, the distance measure is usually used to calculate the deviations between different arguments. After doing an extensive literature review, we have found a great variety of distance measures. Among the existing ones, we observe that the Hamming distance is widely used by researchers in various fields of science. For example, De Luca and Termini

Corresponding author Emili Vizuete-Luciano

E-mail:evizuetel@ub.edu 
(1972) and Kaufman (1975) used it for measuring the entropy of fuzzy sets. Gil-Aluja (1999) applied it in human resource management. Note that a very useful survey about different decision-making methods can be found in Figueira et al. (2005). Usually when dealing with distance measures it is necessary to aggregate them by using an aggregation operator. One of the most common aggregation operators is the weighted average. It aggregates the information giving different degrees of importance to the elements. It has been applied in an incredibly wide range of aggregation operators. Another contribution that we can consider, very useful for the realization of our study, is the ordered weighted average (OWA) operator (Yager 1988; Yager, Kacprzyk 1997). It provides a parameterized family of aggregation operators between the minimum and the maximum. Since its introduction it has been studied by different authors. For example, Canós and Liern (2008) and Merigó and Gil-Lafuente (2011) developed a flexible decision support system in human resource management, $\mathrm{Xu}$ and Chen (2008b) studied priority weights from interval fuzzy preference relations, Yager (1993) developed different families of OWA operators and Yager et al. (2011) presented an updated overview concerning the main trends in this field.

In recent years, it has appeared an interesting alternative which represents a generalization of OWA operators called the induced OWA (IOWA) operator (Yager 2003; Yager, Filev 1999). The main advantage is the reorganization of the information through the use of induced variables. Since its inception, it has been developed by several authors including the generalization of Merigó and Gil-Lafuente (2009) by using generalized and quasi-arithmetic means, intuitionistic fuzzy sets (Atanassov 1986; Xu, Xia 2011) and fuzzy numbers (Wei et al. 2010).

A further interesting approach is the ordered weighted averaging distance (OWAD) operator (Merigó, Gil-Lafuente 2010; Xu, Chen 2008a). It is a distance measure that provides a parameterized family of distance aggregation operators between the minimum distance and the maximum distance. The OWAD operator can be generalized by using order inducing variables in the reordering process of the information forming the induced OWAD (IOWAD) operator (Merigó, Casanovas 2011a). Further generalizations are possible by using other techniques such as the Euclidean distance (Merigó, Casanovas 2011b), the Minkowski distance (Merigó, Casanovas 2011c), the adequacy coefficient (Merigó et al. 2011a), the index of maximum and minimum level (Merigó et al. 2011b), moving averages (Merigó, Yager 2013), probabilities (Merigó 2013; Merigó et al. 2013), interval numbers (Zeng et al. 2013) and intuitionistic fuzzy sets (Zeng, Su 2011).

In this paper, we present a new model for the assignment process by using the Hungarian method (Kuhn 1955). Note that in the literature there are a lot of methods for dealing with the assignment process (Kuhn 2012; Lawler, Wood 1966). We introduce the use of the OWAD operator in this framework. The main advantage is that we can provide a more complete representation of this process considering results from the minimum distance to the maximum one. Therefore, we can consider several pessimistic and optimistic attitudes of the decision maker in order to obtain a more efficient decision. Next, we introduce a further generalization by using the IOWAD operator. Thus, we can assess the aggregation considering complex reordering processes that deals with high degrees of uncertainty in the information. We also analyse a wide range of particular cases included in this aggre- 
gation process such as the minimum distance, the normalized Hamming distance and the weighted Hamming distance.

We also develop an application in financial management. We analyse the optimal assignment of financial products for each decision maker according to his attitudinal character. We see that we can use a wide range of OWAD and IOWAD operators from the minimum distance to the maximum one. Note that each particular case may provide different results leading to a different assignment process. The main advantage of this approach is that it provides a more complete picture of all the possible scenarios. Thus, the decision maker can consider the entire available situation and select the alternative that is in closest accordance with his interest.

This work is structured as follows: In section 1 we present the preliminary concepts. In Section 2, we suggest a new approach for dealing with the Hungarian Algorithm by using the OWAD, the IOWAD and the GOWAD operators. Section 3 analyses the applicability of this framework in financial management. Finally in the Conclusions we summarize the main results of this paper.

\section{Theoretical foundations}

In this section, we present the theoretical definitions and theorems related to the OWA operator and the Hungarian method.

\subsection{The OWA operator}

The OWA operator was introduced by Yager (1988). It provides a parameterized family of aggregation operators that has been used by many authors (Belles et al. 2013; Cheng et al. 2009; Dong et al. 2010; Karayiannis 2000). The principal advantage of the OWA operator is that it reorders arguments based on their values. The weights are associated with a particular position in the ordering. This reordering process introduces nonlinearity into an otherwise linear process. It can be defined as follows:

Definition 1. An OWA operator of dimension $n$ is a mapping OWA: $R_{n}^{n} \rightarrow R$ that has an associated weighting vector $w=\left(w_{1}, w_{2}, \ldots, w_{n}\right)$. with $w_{j} \in[0,1]$ and $\sum_{j=1}^{n} w_{j}=1$ such that:

$$
\operatorname{OWA}\left(a_{1}, a_{2}, \ldots, a_{n}\right)=\sum_{j=1}^{n} w_{j} b_{j},
$$

where $b_{j}$ is the $j$ th largest of $\left(a_{1}, a_{2}, \ldots, a_{n}\right)$.

The OWA operator is commutative, monotonic, bounded and idempotent. Since its introduction, it has been studied by a lot of authors. For further reading see, for example Merigó and Wei (2011); Yager and Kacprzyk (1997) and Yager et al. (2011).

\subsection{The induced OWA operator}

If we use order inducing variables in the reordering step of the aggregation, we can obtain the induced OWA operator (IOWA) (Yager, Filev 1999). Since its appearance, some 
researchers have used this induced operator. For example, Merigó and Gil-Lafuente (2009) developed a generalization by using generalized and quasi-arithmetic means and $\mathrm{Xu}$ and $\mathrm{Da}$ (2003) introduced a geometric version and applied it in group decision making. The IOWA operator represents an extension of the first. Its main difference is that the reordering step is carried out with order inducing variables. This operator includes a particular case. It can be defined as follows:

Definition 2. An IOWA operator of dimension $n$ is a mapping IOWA: $R^{n} \times R^{n} \rightarrow R$ an associated weighting vector $w$ of dimension $n$ with $\sum_{j=1}^{n} w_{j}=1$ and $w_{j} \in[0,1]$, and a set of
order inducing variables $u_{j}$, such that:

$$
\operatorname{IOWA}\left(\left\langle u_{1}, a_{1}\right\rangle,\left\langle u_{2}, a_{2}\right\rangle, \ldots,\left\langle u_{n}, a_{n}\right\rangle\right)=\sum_{j=1}^{n} w_{j} b_{j},
$$

where $b_{j}$ is the $a_{j}$ value or the IOWA pair $\left\langle u_{1}, a_{1}\right\rangle$ is the $j$ th largest $u_{i}, u_{i}$ is the order inducing variable and $a_{j}$ is the argument variable.

We remark that the IOWA operator is also monotonic, bounded, idempotent and commutative. Note that in the case of ties between order inducing variables in the reordering process, it is necessary to make an adjustment in the aggregation. We recommend the methodology suggested by Yager and Filev (1999) concerning the use of the arithmetic mean between the tied arguments.

\subsection{The OWA distance operator}

The OWAD operator (Merigó, Gil-Lafuente 2010; Xu, Chen 2008a) is an aggregation operator and it is an extension of the traditional normalized Hamming distance by using OWA operators. The purpose of this operator is the reordering of the individual distances according to their values. An interesting advantage of this operator is the possibility of calculating the distance between two fuzzy sets modifying the results according to the interests of the decision maker. It can be defined as follows:

Definition 3. An OWAD operator of dimension $n$ is a mapping OWAD: $[0,1]^{n} \times[0,1]^{n} \rightarrow[0,1]$ an associated weighting vector $w$, with $\sum_{j=1}^{n} w_{j}=1$ and $w_{j} \in[0,1]$
such that:

$$
\operatorname{OWAD}\left(\left\langle u_{1}, u_{1}^{(k)}\right\rangle,\left\langle u_{2} u_{2}^{(k)}\right\rangle, \ldots,\left\langle u_{n}, u_{n}^{(k)}\right\rangle\right)=\sum_{j=1}^{n} w_{j}, D_{j},
$$

where $D_{j}$ represents the $j$ th largest of the individual distances $\left|u_{i}-u_{i}^{(k)}\right|$, with $u_{i}$ and $u_{i}^{(k)} \in[0,1]$, and $k=1,2, \ldots, m$.

It is necessary to remark that this operator can be generalized to all the real numbers $R$ by using OWAD: $R^{n} \times R^{n} \rightarrow R$. Because it is possible to distinguish between ascending and descending orders, the weights of these operators are related by $w_{j}=w_{n-j+1}^{*}$, where $w_{j}$ is the $j$ th weight of the descending OWAD (DOWAD) operator and $w_{n-j+1}^{*}$ the $j$ th weight of the ascending OWAD (AOWAD) operator. 


\subsection{The induced OWA distance operator}

When we use the IOWA operator in the normalization process of the Hamming distance we can obtain the IOWAD operator. Chen and Zhou (2011) presented an approach to group decision making based on this operator, Merigó and Casanovas (2011b) studied its application in financial decision making. The reordering of the individual distances is developed with order inducing variables. In a case of two sets $X=\left\{x_{1}, x_{2}, \ldots, x_{n}\right\}$ and $Y=\left\{y_{1}, y_{2}, \ldots, y_{n}\right\}$. It can be defined as follows:

Definition 4. An IOWAD opetor of dimension $n$ is a mapping IOWAD: $R^{n} \times R^{n} \times R^{n} \rightarrow R$ with associated weighting vector $W$, such that $w_{j} \in[0,1]$ with $W=\sum_{j=1}^{n} w_{j}=1$, according to
the following formula:

$$
\operatorname{IOWAD}\left(\left\langle u_{1}, x_{1}, y_{1}\right\rangle,\left\langle u_{2}, x_{2}, y_{2}\right\rangle, \ldots,\left\langle u_{n}, x_{n}, y_{n}\right\rangle\right)=\sum_{j=1}^{n} w_{j} b_{j},
$$

where $b_{j}$ is the $\left|x_{i}-y_{i}\right|$ value of the IOWAD triplet $\left\langle u_{i}, x_{i}, y_{i}\right\rangle$ that represents the $j$ th largest $u_{i}, u_{i}$ is the order inducing variable and $\left|x_{i}-y_{i}\right|$ is the argument variable represented in the individual distances.

\subsection{The Hungarian method}

The Hungarian method (Kuhn 1955) was established as an assignment algorithm used in various fields of science by the diversity of applications that can be performed. In recent years we can highlight the contribution made by Goldberger and Tassa (2008), which sets out the main features of this algorithm.

Let $A$ be a $n \times n$ matrix. The following algorithm finds a permutation $\pi \in S_{n}$ that minimizes the expression $\sum_{i} A_{i, \pi(i)}$. In this algorithm, the entries of the matrix $A$ are being modified repeatedly. Zero entries in the modified matrix may be either marked, by a star or by a prime, or unmarked. In addition, each row or column in the matrix may be either covered or uncovered. Initially, there are no starred or primed entries in the matrix and none of the rows or columns is covered:

1. For each row in the matrix $A$ find its minimal entry and subtract it from all entries in that row.

2. For all $1 \leq i, j \leq n$ if $A_{i j}=0$ then star that zeros entry, unless there is already a starred zero in the same row or in the same column.

3. Cover each column that contains a starred zero. If all columns are covered, go to Step 7.

4. Repeat the following procedure until there are no uncovered zeros left and then go to Step 6: find an uncovered zero and prime it. If there are no starred zeros in the same row as this primed zero, go to Step 5. Otherwise, cover this row and uncover the column containing the starred zero.

5. Construct a series of alternating primed and starred zeros as follows: Let $Z_{0}$ be the uncovered primed zero that was found in Step 4 . Let $Z_{1}$ be the starred zero in the column of $Z_{1}$ (if any). Let $Z_{2}$ be the primed zero in the row of $Z_{1}$ (there will always 
be one). Continue to construct this series of alternating primed and starred zeros until it terminates with a primed zero that has no starred zero in its column. Instead each starred zero of the series, star each primed zero of the series, erase all primes and uncover all rows and columns in the matrix. Go to Step 3.

6. Find the smallest uncovered value, add it to every entry in each covered row, and subtract it from every entry in each uncovered column. Go to Step 4.

7. At this stage, in each row of the matrix, as well as in each column, there is exactly one starred zero. The positions of the starred zeros describe an optimal permutation $\pi \in S_{n}$. Output this permutation and stop.

\subsection{Fuzzy Hungarian algorithm}

The Hungarian algorithm can be used with fuzzy information. For example, Gil-Aluja (1999) developed the fuzzy Hungarian algorithm for the efficient assignment of some products based on certain characteristics in different markets.

Developing the Hungarian fuzzy method, based on a distance matrix that we call $[\widetilde{\bar{Q}}]$ or its complementary matrix $[\widetilde{\bar{R}}]$; in order to find the optimal assignment we will start by using a minimum principle.

In most cases these fuzzy relations are not always the same number of rows and columns so they would have to operate with rectangular matrices. For operational reasons, it will be transformed into a square matrix by adding rows or columns needed for introducing fictitious elements, as well as $p_{i j}$ denotes the elements of the matrix, such as if we consider the matrix $[\widetilde{\bar{Q}}]$ or $[\widetilde{\bar{R}}]$.

The algorithm consists of the following steps:

1. Subtract the smallest value in each row or column based on what we have added to make the matrix square. In the case of the rows, we will have $u=\min _{j} p_{i j}$, obtaining $p_{i j}-u_{i}=p_{i j}-\min _{j} p_{i j}$; or $u_{j}=\min _{j} p_{i j}$ in the case of columns getting $p_{i j}-u_{j}=p_{i j}-\min _{i} p_{i j}$. We apply the same process in each column, $v_{j}=\min _{i}\left(p_{i j}-u_{i}\right)$ or row $v_{i}=\min _{j}\left(\stackrel{i}{p_{i j}}-u_{j}\right)$. This means that at least we have one 0 in each column and row in a matrix whose elements take values $p_{i j}-\left(u_{i}-v_{j}\right)$ or $p_{i j}-\left(u_{j}-v_{i}\right)$.

2. We analyze if it is possible to proceed with an assignment in the case that the $p_{i j}$ values of the solution are all zero. If so, we get an optimum. Otherwise is necessary to continue with the process as follows:

a) We search for the row of the matrix that contains less zeros.

b) Mark one of the zeros of each row and delete the other zeros that appear in the row and column to which it belongs the zero we have marked.

c) Repeat this process as many times as necessary in the rows that has more zeros to be marked.

3. We will get the least number of rows and columns that contain all zeros and we will continue the following process:

a) Mark with an arrow $\leftarrow$ the rows that does not exist any zero marked. 
b) Mark with an arrow $\uparrow$ the columns in which there exists a zero deleted in a row marked with an arrow.

c) Indicate with an arrow $\leftarrow$ the rows where there is a zero marked in a column shown with an arrow.

d) Repeat steps b) and c) as many times as necessary until we cannot form more rows or columns.

e) Draw a line in the rows not marked by arrows and a line in the columns marked by arrows. The result we get constitutes the minimum number of rows and columns with zeros marked or deleted.

4. Eventually, move some zeros. We choose the smallest value of non-marked elements at the matrix. This number is subtracted from the non-marked elements and we sum them to the elements of the marked rows. We obtain a matrix with the elements $p_{i j}$.

5. With this new matrix whose elements are $p_{i j}$, return to Step 2 following the same process shown above.

The solution obtained is not unique and it is important to note that we may find other solutions.

\section{OWA operators in the Hungarian algorithm}

In this section we introduce the new approach. First we analyse the case with the OWAD operator. Next, we extend this approach by using induced aggregation operators. We end the section studying a general framework that uses generalized aggregation operators.

\subsection{Using the OWAD operator in the Hungarian algorithm}

The Hungarian algorithm is an efficient assignment process. This algorithm is based on the similarity (or dissimilarity) between the elements considered. However, in real world problems, when calculating the similarity, we need to use a technique that permits to do so such as a distance measure. A very common one used in the Hungarian algorithm is the Hamming distance (Hamming 1950). When dealing with similarities, we have to normalize the distance. The most common way for doing so is by using the arithmetic mean where we give the same importance to all the elements obtaining the normalized (or relative) Hamming distance. Another possibility is by using the weighted average where we assume that the elements are not equally important in the aggregation process forming the weighted Hamming distance. For the formulation used in fuzzy set theory, see, for example Kaufmann (1975) and Szmidt and Kacprzyk (2000).

In this paper, we suggest the use of the OWA operator in the normalized process of the Hamming distance. Thus, we use the OWAD operator (Merigó, Gil-Lafuente 2010; $\mathrm{Xu}$, Chen 2008a) in the assignment process. Its main advantage is that we can provide a parameterized family of distance aggregation operators between the minimum and the maximum. Thus, we can analyse several similarity relations from the minimum to the maximum according to our particular attitude in the specific problem considered. It is very useful because we can consider our normal position when forming the similarity relations 
but at the same time we can under or overestimate this position and see if the results are the same or some important changes may appear when dealing with the assignment process. That is, the assignment process may be different depending on the particular type of OWAD operator used.

When dealing with the OWAD operator, we have to use the following formulation as it has been explained in Definition 3 for two sets $X=\left\{X_{1}, X_{2}, \ldots, X_{n}\right\}$ and $Y=\left\{Y_{1}, Y_{2}, \ldots, Y_{n}\right\}$ :

$$
d(X, Y)=\operatorname{OWAD}\left(\left\langle x_{1}, y_{1}\right\rangle,\left\langle x_{2}, y_{2}\right\rangle, \ldots,\left\langle x_{n}, y_{n}\right\rangle\right)=\sum_{j=1}^{n} w_{j} D_{j},
$$

where $D_{j}$ represents the $j$ th largest of the individual distances $\left|x_{i}-y_{i}\right|$, with $x_{i}$ and $y_{i} \in[0,1], \sum_{j=1}^{n} w_{j}=1$ and $w_{j} \in[0,1]$.

Thus, we have to use it to calculate all the similarity relations between the elements of the set $T=\left\{T_{1}, T_{2}, \ldots, T_{m}\right\}$ and $Z=\left\{Z_{1}, Z_{2}, \ldots, Z_{p}\right\}$, in order to form the matrix $[R]$ as it is shown in Table 1 .

Table 1 . Similarity relations between $T$ and $Z$

\begin{tabular}{cccccccc}
\hline & & $Z_{1}$ & $Z_{2}$ & $\ldots$ & $Z_{k}$ & $\ldots$ & $Z_{p}$ \\
\hline \multirow{6}{*}[R]{} & $T_{1}$ & $d\left(T_{1}, Z_{1}\right)$ & $d\left(T_{1}, Z_{1}\right)$ & $\ldots$ & $d\left(T_{1}, Z_{k}\right)$ & $\ldots$ & $d\left(T_{1}, Z_{p}\right)$ \\
\cline { 2 - 8 } & $T_{2}$ & $d\left(T_{2}, Z_{1}\right)$ & $d\left(T_{2}, Z_{2}\right)$ & $\ldots$ & $d\left(T_{2}, Z_{k}\right)$ & $\ldots$ & $d\left(T_{2}, Z_{p}\right)$ \\
\cline { 2 - 9 } & $\ldots$ & $\ldots$ & $\ldots$ & $\ldots$ & $\ldots$ & $\ldots$ & $\ldots$ \\
\cline { 2 - 8 } & $\mathrm{T}_{\mathrm{h}}$ & $d\left(T_{h}, Z_{1}\right)$ & $d\left(T_{h}, Z_{2}\right)$ & $\ldots$ & $d\left(T_{h}, Z_{k}\right)$ & $\ldots$ & $d\left(T_{h}, Z_{p}\right)$ \\
\cline { 2 - 8 } & $\ldots$ & $\ldots$ & $\ldots$ & $\ldots$ & $\ldots$ & $\ldots$ & $\ldots$ \\
\cline { 2 - 8 } & $\mathrm{T}_{\mathrm{m}}$ & $d\left(T_{m}, Z_{1}\right)$ & $d\left(T_{m}, Z_{2}\right)$ & $\ldots$ & $d\left(T_{m}, Z_{k}\right)$ & $\ldots$ & $d\left(T_{m}, Z_{p}\right)$ \\
\hline
\end{tabular}

As can see, we calculate the distance by using the OWAD operator between each $T_{h}$ and $Z_{k}$. Note that with the OWAD operator we can obtain a wide range of results between the minimum and the maximum distance according to our attitude in the aggregation process.

Once we have the similarity relations, it is straightforward to solve the assignment process with the Hungarian algorithm following the Steps 1-7 given in Section 1.5. Furthermore, note that it is possible to analyse a wide range of particular cases. The main idea is that the decision maker will use the particular type that is in closest accordance to his interests.

Remark 1. It is possible to distinguish between ascending and descending orders in the OWAD operator. The weights of these operators are related by $w_{j}=w_{n-j+1}^{*}$, where $w_{j}$ is the jth weight of the descending OWAD (DOWAD) operator and $w_{n-j+1}^{*}$ the jth weight of the ascending OWAD (AOWAD) operator.

Remark 2. Another interesting transformation is possible by using $w_{i}^{*}=\left(1+w_{i}\right) /(n-1)$. Furthermore, we can also analyze situations with buoyancy measures (Yager 1993). In this case, we assume that $w_{i} \geq w_{j}$, for $i>j$. Note that it is also possible to consider a stronger case known as extensive buoyancy measure where $w_{i}>w_{j}$, for $i<j$. Additionally, we can 
also consider the contrary case, that is, $\mathrm{w}_{\mathrm{i}} \leq \mathrm{w}_{\mathrm{j}}$, for $i<j$, and the contrary case of the extensive measure $w_{i}<w_{j}$, for $i<j$.

Remark 3. The maximum distance is found when $w_{1}=1$ and $w_{j}=0$ for all $j \neq 1$ and the minimum distance when $w_{n}=1$ and $w_{j}=0$ for all $j \neq n$. A generalization of the previous ones is the step-OWAD. It sets $w_{k}=1$ and $w_{j}=0$ for all $j \neq k$. Note that if $k=1$, we get the maximum and if $k=n$, the minimum distance.

Remark 4. The normalized Hamming distance is obtained when $w_{j}=1 / n$ for all $j$, and the weighted Hamming distance is obtained when the ordered position of $i$ is the same as the ordered position of $j$.

Remark 5. The olympic-OWAD is generated when $w_{1}=w_{n}=0$, and for all others $w_{j^{*}}=1 /(n-2)$. Following Merigó and Gil-Lafuente (2010), it is possible to develop a general form of the olympic-OWAD by considering that $w_{j}=0$ for $j=1,2, \ldots, k, n, n-1, \ldots, n-k+1$, and for all others $w_{j^{*}}=1 /(n-2 k)$, where $k<n / 2$.

Remark 6. Moreover, we can develop the contrary case of the previous one by using $w_{j}=(1 / 2 k)$ for $j=1,2, \ldots, k, n, n-1, \ldots, n-k+1$, and $w_{j}=0$, for all other values, where $k<n / 2$.

Remark 7. Another interesting family is the S-OWAD operator. It can be subdivided into three classes: the "or-like," the "and-like" and the generalized S-OWAD operators.

- The generalized S-OWAD operator is obtained if

$w_{1}=(1 / n)(1-(\alpha+\beta))+\alpha, w_{n}=(1 / n)(1-(\alpha+\beta))+\beta$, and $w_{j}=(1 / n)(1-(\alpha+\beta))$ for $j=2$ to $n-1$, where $\alpha, \beta \in[0,1]$ and $\alpha+\beta \leq 1$.

- If $\alpha=0$, the generalized S-OWAD operator becomes the "and-like" S-OWAD operator.

- If $\beta=0$, it becomes the "or-like" S-OWAD operator.

A further interesting issue is to analyse some of the main properties of the OWAD operator. It is commutative from the context of an OWA aggregation because $f\left(\left\langle u_{1}, x_{1}, y_{1}\right\rangle, \ldots,\left\langle u_{n}, x_{n}, y_{n}\right\rangle\right)=f\left(\left\langle u_{1}, c_{1}, d_{1}\right\rangle, \ldots,\left\langle u_{n}, c_{n}, d_{n}\right\rangle\right)$, where $\left(\left\langle u_{1}, x_{1}, y_{1}\right\rangle, \ldots,\left\langle u_{n}, x_{n}, y_{n}\right\rangle\right)$, is any permutation of the arguments $\left(\left\langle u_{1}, c_{1}, d_{1}\right\rangle, \ldots,\left\langle u_{n}, c_{n}, d_{n}\right\rangle\right)$. It is also commutative from the context of a distance measure because $f\left(\left\langle u_{1}, x_{1}, y_{1}\right\rangle, \ldots,\left\langle u_{n}, x_{n}, y_{n}\right\rangle\right)=f\left(\left\langle u_{1}, y_{1}, x_{1}\right\rangle, \ldots,\left\langle u_{n}, y_{n}, x_{n}\right\rangle\right)$. Moreover, it is monotonic because if $\left|x_{i}-y_{i}\right| \geq\left|c_{i}-d_{i}\right|$, for all $i$, then $f\left(\left\langle u_{1}, x_{1}, y_{1}\right\rangle, \ldots,\left\langle u_{n}, x_{n}, y_{n}\right\rangle\right) \geq$ $f\left(\left\langle u_{1}, c_{1}, d_{1}\right\rangle, \ldots,\left\langle u_{n}, c_{n}, d_{n}\right\rangle\right)$. It is also bounded since $\min \left\{\left|x_{i}-y_{i}\right|\right\} \leq$ $f\left(\left\langle u_{1}, x_{1}, y_{1}\right\rangle, \ldots,\left\langle u_{n}, x_{n}, y_{n}\right\rangle\right) \leq \max \left\{\left|x_{i}-y_{i}\right|\right\}$. Furthermore, it is idempotent because if $\left|x_{i}-y_{i}\right|=a$, for all $i$, then $f\left(\left\langle u_{1}, x_{1}, y_{1}\right\rangle, \ldots,\left\langle u_{n}, x_{n}, y_{n}\right\rangle\right)=a$. It also accomplishes non negativity as $f\left(\left\langle u_{1}, x_{1}, y_{1}\right\rangle, \ldots,\left\langle u_{n}, x_{n}, y_{n}\right\rangle\right) \geq 0$. Finally, it is reflexive since $f\left(\left\langle u_{1}, x_{1}, x_{1}\right\rangle, \ldots,\left\langle u_{n}, x_{n}, x_{n}\right\rangle\right)=0$.

In order to analyse the aggregation, we can use several measures for characterizing the weighting vector. A very common technique for doing so is the orness measure $\propto(W)$. It can be defined as follows: 


$$
\alpha(W)=\sum_{j=1}^{n}\left(\frac{n-j}{n-1}\right) w_{j},
$$

As we can see, $\propto(W) \in[0,1]$. Note that the more of $\propto(W)$ closer to 1 the more of the weight we locate at the top of $W$ and vice versa.

Another useful measure is the balance operator. It permits to analyse if the balance of the aggregations closer to the minimum or to the maximum. It is defined as follows:

$$
\operatorname{Bal}(W)=\sum_{j=1}^{n}\left(\frac{n+1-2 j}{n-1}\right) w_{j} .
$$

In this case, $\operatorname{Bal}(W) \in[-1,1]$. Note that if $\operatorname{Bal}(W)$ is positive, the aggregation tends to the maximum and if it is negative, it tends to the minimum.

\subsection{IOWAD operators in the Hungarian algorithm}

An interesting extension of the OWAD operator (Merigó, Gil-Lafuente 2010) that can be used in the Hungarian algorithm is the IOWAD operator by Merigó and Casanovas (2011a, $2011 b, 2011 c)$. Its main advantage is that it deals with complex reordering processes in the aggregation. Thus, we can consider complex environments where the information may have different meanings than the usual numerical scale such as in the analysis of the temperature of the body where the optimal result is 36 or 37 degrees, and higher or lower results are not optimal.

By using the IOWAD operator in the Hungarian algorithm we can provide a more complete framework for representing the information when using distance measures in the analysis. Note that the IOWAD includes the OWAD operator as a particular case. The assignment process when using the IOWAD operator and the Hungarian algorithm can be described as follows:

Step 1. Calculate the distances between the two set of elements $T=\left\{T_{1}, T_{2}, \ldots, T_{N}\right\}$ and $Z=\left\{Z_{1}, Z_{2}, \ldots, Z_{N}\right\}$ by using:

$$
\operatorname{IOWAD}\left(\left\langle u_{1}, x_{1}, y_{1}\right\rangle,\left\langle u_{2}, x_{2}, y_{2}\right\rangle, \ldots,\left\langle u_{n}, x_{n}, y_{n}\right\rangle\right)=\sum_{j=1}^{n} w_{j} b_{j},
$$

where $b_{j}$ is the $\left|x_{i}-y_{i}\right|$ value of the IOWAD triplet $\left\langle u_{i}, x_{i}, y_{i}\right\rangle$ that represents the $j$ th largest $u_{i}, u_{i}$ is the order inducing variable and $\left|x_{i}-y_{i}\right|$ is the argument variable represented in the individual distances.

Step 2. Thus, we obtain $d\left(T_{h}, Z_{k}\right)$ for all $h$ and $k$. That is, the fuzzy relations between $T$ and $Z$. The results can be represented in a similar way as it is presented for the OWAD operator in Table 1.

Step 3. Next, analyse if we have the same number of rows and columns. If so, continue with the algorithm. If not, we have to add additional columns or rows until both are equal.

Step 4. Subtract the smallest value of each row in case we have added a column and the smallest value of each column if we have added a row. This process is explained in Section 1.6. 
Step 5. Analyse if it is possible an assignment in case the values of $p_{i j}$ are all zero. If so, we get an optimum. If not, we continue with the process.

Step 6. Consider the row with less zeros. Mark one of the zeros of each row and delete the rest of the zeros of the row and the column of the zero marked. Repeat this process with the rows that have more and more zeros until there is no zero to be marked.

Step 7. Indicate with an arrow $\leftarrow$ the rows where there is not any zero marked.

Step 8. Next, indicate with an arrow $\uparrow$ the columns in which there exists a zero deleted in a row marked with an arrow. Finally, mark with an arrow $\leftarrow$ the rows where there is a zero marked in a column indicated with an arrow.

Step 9. Repeat Step 8 until it is not possible to consider more rows or columns.

Step 10. Draw a line in the rows not marked by arrows and a line in the columns marked by arrows. These rows and columns constitute the lowest number of them that possess zeros marked or deleted.

Step 11. Eventually, move some of the zeros. For doing so, we choose the smallest value among the elements of the matrix that has not been marked by arrows. This result is subtracted from the elements of the columns not marked and it is added to the elements of the rows marked. We obtain a matrix with the elements $p_{i j}^{*}$.

Step 12. With the new matrix which elements are $p_{i j}{ }^{*}$, we go back to Step 5 , following the same process used for the matrix with the elements $p_{i j}$. If we find an optimal solution, we stop and reach the final point. Otherwise, we continue with Steps 6 to 11. If necessary, go back to Step 5 .

Note that we may find a solution that may not be unique, so it is possible to obtain other solutions.

In this assignment process we can also study a wide range of particular cases following the methodology explained in Remarks $1-7$ including the maximum, the minimum, the step-IOWAD and the olympic-IOWAD operator. Moreover, we can also analyse similar properties including commutativity, monotonicity and reflexivity.

Furthermore, we can study several measures for characterizing the weighting vector (Yager 1988; 2002). For example, the entropy of dispersion is defined as follows:

$$
H(W)=-\sum_{j=1}^{n} w_{j} \ln \left(w_{j}\right) .
$$

If $w_{j}=1$ for some $j$, then $H(W)=0$, and the least amount of information is used and if $w_{j}=1 / n$ for all $j$, then, the amount of information used is maximum.

Another measure that can be used is the divergence of $W$ defined in the following way:

$$
\operatorname{Div}(W)=\sum_{j=1}^{n} w_{j}\left(\frac{n-j}{n-1}-\alpha(W)\right)^{2} .
$$

Note that further extensions could be developed in a similar way as it is explained by Merigó and Casanovas (2011a) by using mixture operators, Choquet integrals and so on. 


\subsection{Generalized aggregation operators in the Hungarian algorithm}

In order to provide a general representation of the assignment process by using distance measures we can use generalized aggregation operators such as the generalized mean (Merigó, Casanovas 2011c) and the quasi-arithmetic mean (Fodor et al. 1995; Merigó, GilLafuente 2009). Thus, we will obtain a general framework that will include a wide range of particular including the use of the OWAD and the IOWAD operators in the analysis. Note that when we use the generalized mean with distance measures we are using the Minkowski distance. First, let us look to the case with the OWAD operator. Therefore, we are using the generalized ordered weighted averaging distance (GOWAD) operator (or Minkowski OWAD (MOWAD) operator) (Merigó, Casanovas 2011c; Xu, Chen 2008a) that can be defined as follows.

Definition 5. A Minkowski OWAD (MOWAD) operator of dimension $\mathrm{n}$ is a mapping MOWAD: $R_{n} R_{n} \rightarrow R$ that has an associated weighting vector $W$ of dimension $n$ with $\sum_{j=1}^{n} w_{j}=1$ and $w_{j} \in[0,1]$ such that:

$$
\operatorname{MOWAD}\left[\left(a_{1}, b_{1}\right),\left(a_{2}, b_{2}\right), \ldots,\left(a_{n}, b_{n}\right)\right]=\left(\sum_{j=1}^{n} w_{j} D_{j}^{\lambda}\right)^{1 / \lambda},
$$

where $D j$ is the $j$ th largest of the individual distance $\left|a_{i}-b_{i}\right|$ between $A$ and $B$ and $\lambda$ is a parameter such that $\lambda \in-\infty, \infty$.

As we can see, we can use a wide range of particular cases by using different values in the parameter $\lambda$. For example:

- If $\lambda=1$, we use the OWAD operator as shown in Definition 3.

- If $\lambda=2$, we obtain the Euclidean OWAD (EOWAD) operator (Merigó, Casanovas 2011b):

$$
\operatorname{EOWAD}\left[\left(a_{1}, b_{1}\right),\left(a_{2}, b_{2}\right), \ldots,\left(a_{n}, b_{n}\right)\right]=\sqrt{\sum_{j=1}^{n} w_{j} D_{j}^{2}} .
$$

- If $\lambda=3$, we form the cubic OWAD (COWAD) operator:

$$
\operatorname{COWAD}\left[\left(a_{1}, b_{1}\right),\left(a_{2}, b_{2}\right), \ldots,\left(a_{n}, b_{n}\right)\right]=\left(\sum_{j=1}^{n} w_{j} D_{j}^{3}\right)^{1 / 3} .
$$

- If $\lambda=-1$, we get the harmonic OWAD (HOWAD) operator:

$$
\operatorname{HOWAD}\left[\left(a_{1}, b_{1}\right),\left(a_{2}, b_{2}\right), \ldots,\left(a_{n}, b_{n}\right)\right]=\left(\sum_{j=1}^{n} w_{j} D_{j}^{-1}\right)^{1 /-1}=\frac{1}{\sum_{j=1}^{n} \frac{w_{j}}{D_{j}}} .
$$

The MOWAD operator can be generalized by using quasi-arithmetic means. Thus, we obtain the quasi-arithmetic OWAD (Quasi-OWAD) operator (Merigó, Casanovas 2011a). It can be defined as follows.

Definition 6. A Quasi-OWAD operator of dimension $n$ is a mapping Quasi-OWAD: 

$R_{n} R_{n} \rightarrow R$ that has an associated weighting vector $W$ of dimension $n$ with $\sum_{j=1}^{n} w_{j}=1$ and
$w_{j} \in[0,1]$ such that:

$$
\text { Quasi-OWAD }\left[\left(a_{1}, b_{1}\right),\left(a_{2}, b_{2}\right), \ldots,\left(a_{n}, b_{n}\right)\right]=g^{-1}\left(\sum_{j=1}^{n} w_{j} g\left(D_{j}\right)\right) \text {, }
$$

where $D j$ is the $j$ th largest of the individual distance $\left|a_{i}-b_{i}\right|$ between $A$ and $B$ and $g\left(D_{j}\right)$ is a strictly continuous monotonic function.

As we can see, the Quasi-OWAD operator includes the MOWAD operator as a particular case and a wide range of other ones. For example:

- If $g\left(D_{j}\right)=D_{j}^{\lambda}$, we obtain the MOWAD operator.

- If $g\left(D_{j}\right)=D_{j}$, we the get the OWAD operator.

- If $g\left(D_{j}\right)=D_{j}^{3}$, we form the EOWAD operator.

- If $g\left(D_{j}\right)=D_{j}^{3}$, the Quasi-OWAD operator becomes the COWAD operator.

- If $g\left(D_{j}\right)=D_{j}^{-1}$, we obtain the HOWAD operator.

Furthermore, we can extend the MOWAD and the Quasi-OWAD operators by using induced aggregation operators (Merigó, Casanovas 2011c). Note that a lot of other cases could be considered following the literature concerning quasi-arithmetic means (Beliakov et al. 2007; Merigó, Gil-Lafuente 2009).

Once we have established the type of distance measure to be used in the assignment process forming the similarity relations shown in Table 1, we could continue the Hungarian algorithm in a similar way as explained in Section 2.2.

\section{Illustrative example}

In the following, we develop a simple numerical example of the new approach. The focus is on assignment decision making problems based on the Hungarian algorithm. Note that in the literature there are many other methods for decision making (Gil-Aluja 1999; Han, Liu 2011; Vizuete et al. 2013; Wei et al. 2012).

Assume that an enterprise wants to invest some money in one product. After careful analysis of the different possibilities that the markets offer, the group of experts of the enterprise considers six possible investments:

$-P_{1}=$ Hedge Funds.

$-P_{2}=$ Investment Funds.

$-P_{3}=$ Bonds.

$-P_{4}=$ Fixed Income Notes.

$-P_{5}=$ Stocks.

$-P_{6}=$ Equity Derivatives.

When analysing the investments, the experts have considered the following general characteristics:

$-C_{1}=$ Risks of the investment. 
$-C_{2}=$ Difficulty of the investment.

$-C_{3}=$ Benefits in the long term.

$-C_{4}=$ Benefits in the mid term.

$-C_{5}=$ Benefits in the short term.

$-C_{6}=$ Social responsible investment (SRI).

$-C_{7}=$ Others aspects.

The companies involved in the following decision process that can invest in these financial products are the following:

$-E_{1}=$ Enterprise A.

$-E_{2}=$ Enterprise B.

$-E_{3}=$ Enterprise C.

$-E_{4}=$ Enterprise D.

$-E_{5}=$ Enterprise E.

With this information, the group of experts describes each financial product according to the characteristics established in aggregated form the results are shown in Table 2 . We assume that each company has similar characteristics so they are more or less equally qualified for carrying out the strategic investment process and its aggregated subjective opinions are shown in Table 3. The results are valuations (numbers) between 0 and 1 being 1 the best result and 0 the worst result.

In the first case we consider the seven characteristics with the normalized Hamming distance (Gil-Aluja 1999). We assume that $\mathrm{W}=(0.3,0.2,0.2,0.1,0.1,0.1,0)$ in the OWAD operator and $U=(12,10,9,5,7,15,3)$ in the IOWAD operator. Note that order inducing variables $\mathrm{U}$ are provided by the experts when they analyse the information. With this information, it is possible to develop different methods for calculating the Hungarian algorithm.

In this example, we consider the Hamming distance, the OWAD operator and the IOWAD operator. In the first case, the distances that we obtain are shown in Table 4 . In the second case, the aggregated results are shown in Table 5. The third operator is presented in Table 6 . Note that many other aggregation operators could be used in the analysis by using different values in the parameter $\lambda$ of Eq. (11). In this example, it is implicitly assumed $\lambda=1$, which is the most common and practical case in decision making problems.

The results of Table 4, 5 and 6 are obtained by using Remark 4 and Eqs (3) and (4). For example, in Table $4, E_{1}$ with $P_{1}$ is obtained as follows: $d\left(E_{1}, P_{1}\right)=(1 / 7)[|0.8-0.6|+\mid 0.7-$ $0.5|+| 0.8-0.8|+| 0.7-0.6|+| 0.6-0.5|+| 0.5-0.5|+| 0.6-0.7 \mid]=0.10$. And so on for the rest of the cases. We develop a Hungarian algorithm by using the Hamming distance. The results are shown in Table 7.

If we analyse the sum of distances in the original matrix, we obtain that $0.14+0.07+$ $0.09+0.09+0.11+1=1.50$, if we subtract the value of the fictitious element, we obtain $1.50-1=0.50$, this is an optimal solution. With these calculations the optimal assignment by using the Hamming distance is as follows: 
Table 2. Characteristics of the financial products

\begin{tabular}{cccccccc}
\hline & $C_{1}$ & $C_{2}$ & $C_{3}$ & $C_{4}$ & $C_{5}$ & $C_{6}$ & $C_{7}$ \\
\hline$P_{1}$ & 0.8 & 0.7 & 0.8 & 0.7 & 0.6 & 0.5 & 0.6 \\
\hline$P_{2}$ & 0.7 & 0.6 & 0.7 & 0.7 & 0.5 & 0.8 & 0.6 \\
\hline$P_{3}$ & 0.4 & 0.7 & 0.6 & 0.7 & 0.7 & 0.6 & 0.6 \\
\hline$P_{4}$ & 0.6 & 0.7 & 0.5 & 0.6 & 0.8 & 0.7 & 0.7 \\
\hline$P_{5}$ & 0.8 & 0.4 & 0.7 & 0.8 & 0.8 & 0.4 & 0.7 \\
\hline$P_{6}$ & 0.8 & 0.7 & 0.7 & 0.8 & 0.7 & 0.5 & 0.7 \\
\hline
\end{tabular}

Table 3. Characteristics of the enterprises

\begin{tabular}{cccccccc}
\hline & $C_{1}$ & $C_{2}$ & $C_{3}$ & $C_{4}$ & $C_{5}$ & $C_{6}$ & $C_{7}$ \\
\hline$E_{1}$ & 0.6 & 0.5 & 0.8 & 0.6 & 0.5 & 0.5 & 0.7 \\
\hline$E_{2}$ & 0.7 & 0.6 & 0.7 & 0.8 & 0.9 & 0.8 & 0.6 \\
\hline$E_{3}$ & 0.8 & 0.9 & 0.8 & 0.7 & 0.5 & 0.7 & 0.5 \\
\hline$E_{4}$ & 0.6 & 0.8 & 0.9 & 0.8 & 0.7 & 0.5 & 0.8 \\
\hline$E_{5}$ & 0.9 & 0.8 & 0.7 & 0.8 & 0.9 & 0.6 & 0.7 \\
\hline
\end{tabular}

Table 4. Aggregated distances with Hamming

\begin{tabular}{ccccccc}
\hline & $P_{1}$ & $P_{2}$ & $P_{3}$ & $P_{4}$ & $P_{5}$ & $P_{6}$ \\
\hline$E_{1}$ & 0.10 & 0.11 & 0.16 & 0.14 & 0.14 & 0.13 \\
\hline$E_{2}$ & 0.14 & 0.07 & 0.14 & 0.13 & 0.13 & 0.11 \\
\hline$E_{3}$ & 0.09 & 0.10 & 0.17 & 0.19 & 0.21 & 0.14 \\
\hline$E_{4}$ & 0.11 & 0.19 & 0.14 & 0.16 & 0.16 & 0.09 \\
\hline$E_{5}$ & 0.13 & 0.17 & 0.16 & 0.14 & 0.11 & 0.07 \\
\hline
\end{tabular}

Table 5. Aggregated distances with OWAD operator

\begin{tabular}{ccccccc}
\hline & $P_{1}$ & $P_{2}$ & $P_{3}$ & $P_{4}$ & $P_{5}$ & $P_{6}$ \\
\hline$E_{1}$ & 0.14 & 0.16 & 0.18 & 0.21 & 0.20 & 0.17 \\
\hline$E_{2}$ & 0.20 & 0.14 & 0.20 & 0.15 & 0.20 & 0.17 \\
\hline$E_{3}$ & 0.13 & 0.15 & 0.24 & 0.24 & 0.31 & 0.18 \\
\hline$E_{4}$ & 0.15 & 0.22 & 0.20 & 0.23 & 0.23 & 0.13 \\
\hline$E_{5}$ & 0.16 & 0.24 & 0.24 & 0.20 & 0.19 & 0.11 \\
\hline
\end{tabular}

Table 6. Aggregated distances with IOWAD operator

\begin{tabular}{ccccccc}
\hline & $P_{1}$ & $P_{2}$ & $P_{3}$ & $P_{4}$ & $P_{5}$ & $P_{6}$ \\
\hline$E_{1}$ & 0.10 & 0.15 & 0.16 & 0.16 & 0.15 & 0.13 \\
\hline$E_{2}$ & 0.18 & 0.05 & 0.18 & 0.12 & 0.19 & 0.15 \\
\hline$E_{3}$ & 0.11 & 0.12 & 0.19 & 0.15 & 0.24 & 0.14 \\
\hline$E_{4}$ & 0.09 & 0.20 & 0.13 & 0.15 & 0.18 & 0.08 \\
\hline$E_{5}$ & 0.12 & 0.19 & 0.16 & 0.16 & 0.17 & 0.09 \\
\hline
\end{tabular}


Table 7. Aggregated results with the Hamming distance

\begin{tabular}{ccccccc}
\hline & $P_{1}$ & $P_{2}$ & $P_{3}$ & $P_{4}$ & $P_{5}$ & $P_{6}$ \\
\hline$E_{1}$ & 0 & 0.02 & 0.03 & $0(1)$. & 0.01 & 0.04 \\
\hline$E_{2}$ & 0.06 & $0(2)$. & 0 & 0 & 0.02 & 0.04 \\
\hline$E_{3}$ & $0(3)$. & 0.03 & 0.05 & 0.04 & 0.10 & 0.07 \\
\hline$E_{4}$ & 0.02 & 0.10 & 0 & 0.03 & 0.03 & $0(4)$. \\
\hline$E_{5}$ & 0.05 & 0.10 & 0.04 & 0.02 & $0(5)$. & 0 \\
\hline$E_{0}$ & 0.05 & 0.05 & $0(6)$. & 0 & 0.01 & 0.05 \\
\hline
\end{tabular}

\section{Assignment process 1}

1. Enterprise 1 assigned with financial product $P_{4}$ (Fixed Income Notes).

2. Enterprise 2 assigned with financial product $P_{2}$ (Investment Funds).

3. Enterprise 3 assigned with financial product $P_{1}$ (Hedge Funds).

4. Enterprise 4 assigned with financial product $P_{6}$ (Equity Derivatives).

5. Enterprise 5 assigned with financial product $P_{5}$ (Stocks).

6. Enterprise 0 assigned with financial product $P_{3}$ (Bonds).

Next, we develop a Hungarian algorithm with the OWAD operator. We assume that $\mathrm{W}=(0.3,0.2,0.2,0.1,0.1,0.1,0)$. The results are shown in Table 8.

Table 8. Aggregated results with the OWAD operator

\begin{tabular}{ccccccc}
\hline & $P_{1}$ & $P_{2}$ & $P_{3}$ & $P_{4}$ & $P_{5}$ & $P_{6}$ \\
\hline$E_{1}$ & 0.02 & 0.01 & $0(1)$. & 0.05 & 0.02 & 0.07 \\
\hline$E_{2}$ & 0.08 & 0 & 0.03 & $0(2)$. & 0.02 & 0.07 \\
\hline$E_{3}$ & 0 & $0(3)$. & 0.07 & 0.08 & 0.13 & 0.08 \\
\hline$E_{4}$ & $0(4)$. & 0.05 & 0 & 0.05 & 0.03 & 0 \\
\hline$E_{5}$ & 0.04 & 0.09 & 0.07 & 0.04 & 0 & $0(5)$. \\
\hline$E_{0}$ & 0.07 & 0.05 & 0.02 & 0.04 & $0(6)$. & 0.09 \\
\hline
\end{tabular}

By using the same process that we use before, we observe that $0.18+0.15+0.15+$ $0.15+0.11=0.74$. In this case we do not add and subtract the fictitious value, and we can obtain an optimal solution. Therefore, the optimal assignment is the following one:

\section{Assignment process 2}

1. Enterprise 1 assigned with financial product $P_{3}$ (Bonds).

2. Enterprise 2 assigned with financial product $P_{4}$ (Fixed Income Notes).

3. Enterprise 3 assigned with financial product $P_{2}$ (Investment Funds).

4. Enterprise 4 assigned with financial product $P_{1}$ (Hedge Funds).

5. Enterprise 5 assigned with financial product $P_{6}$ (Equity Derivatives).

6. Enterprise 0 assigned with financial product $P_{5}$ (Stocks).

Next, we develop a Hungarian algorithm with the IOWAD operator. We assume that $\mathrm{U}=(12,10,9,5,7,15,3)$. The results are shown in Table 9 and 10 . 
Table 9. Aggregated results with the IOWAD operator (1)

\begin{tabular}{ccccccc}
\hline & $P_{1}$ & $P_{2}$ & $P_{3}$ & $P_{4}$ & $P_{5}$ & $P_{6}$ \\
\hline$E_{1}$ & $0(1)$. & 0.08 & 0.01 & 0.02 & 0.00 & 0.03 \\
\hline$E_{2}$ & 0.10 & $0(2)$. & 0.05 & 0 & 0.06 & 0.07 \\
\hline$E_{3}$ & 0 & 0.04 & 0.03 & $0(3)$. & 0.09 & 0.03 \\
\hline$E_{4}$ & 0 & 0.15 & $0(4)$. & 0.03 & 0.05 & 0 \\
\hline$E_{5}$ & 0.03 & 0.13 & 0.02 & 0.03 & 0.03 & $0(5)$. \\
\hline$E_{0}$ & 0.06 & 0.08 & 0 & 0.01 & $0(6)$. & 0.05 \\
\hline
\end{tabular}

Table 10. Aggregated results with the IOWAD operator (2)

\begin{tabular}{ccccccc}
\hline & $P_{1}$ & $P_{2}$ & $P_{3}$ & $P_{4}$ & $P_{5}$ & $P_{6}$ \\
\hline$E_{1}$ & 0 & 0.08 & 0.01 & 0.02 & $0(1)$. & 0.03 \\
\hline$E_{2}$ & 0.10 & $0(2)$. & 0.05 & 0 & 0.06 & 0.07 \\
\hline$E_{3}$ & 0 & 0.04 & 0.03 & $0(3)$. & 0.09 & 0.03 \\
\hline$E_{4}$ & $0(4)$. & 0.15 & 0 & 0.03 & 0.05 & 0 \\
\hline$E_{5}$ & 0.03 & 0.13 & 0.02 & 0.03 & 0.03 & $0(5)$. \\
\hline$E_{0}$ & 0.06 & 0.08 & $0(6)$. & 0.01 & 0 & 0.05 \\
\hline
\end{tabular}

Note that with the IOWAD operator we find that there are two optimal assignment processes as shown in Tables 9 and 10. However, if we analyse both assignments in detail, we see the sum of distances in the original matrix is in the first case without taking the notional value of the assignment $0.10+0.05+0.15+0.13+0.09=0.52$, and for the second assignment process is $0.15+0.05+0.15+0.09+0.09=0.53$. Thus, although both assignment processes are optimal, it seems that the first one $(3 \mathrm{a})$ is better.

\section{Assignment process 3a}

1. Enterprise 1 assigned with financial product $P_{1}$ (Hedge Funds).

2. Enterprise 2 assigned with financial product $P_{2}$ (Investment Funds).

3. Enterprise 3 assigned with financial product $P_{4}$ (Fixed Income Notes).

4. Enterprise 4 assigned with financial product $P_{3}$ (Bonds).

5. Enterprise 5 assigned with financial product $P_{6}$ (Equity Derivatives).

6. Enterprise 0 assigned with financial product $P_{5}$ (Stocks).

\section{Assignment process $\mathbf{3 b}$}

1. Enterprise 1 assigned with financial product $P_{5}$ (Stocks).

2. Enterprise 2 assigned with financial product $P_{2}$ (Investment Funds).

3. Enterprise 3 assigned with financial product $P_{4}$ (Fixed Income Notes).

4. Enterprise 4 assigned with financial product $P_{1}$ (Hedge Funds).

5. Enterprise 5 assigned with financial product (Equity Derivatives).

6. Enterprise 0 assigned with financial product $P_{3}$ (Bonds). 


\section{Conclusions}

We have presented a new approach for decision making in an assignment process by using the OWAD operator. Its main advantage is that we can consider the information in a more complete way by using a parameterized family of aggregation operators from the minimum to the maximum distance. Thus, we can consider optimistic or pessimistic scenarios by under or over estimating the information. We have further extended this approach by using induced aggregation operators. Therefore, we have been able to analyse complex reordering processes where the information is not clearly known.

We have also generalized it by using generalized and quasi-arithmetic means forming the generalized OWAD (GOWAD) operator (also known as the Minkowski OWAD) and the quasi-arithmetic OWAD (Quasi-OWAD) operator. We have seen that these approaches include a wide range of particular cases including the Euclidean OWAD operator. A similar generalization has been developed by using the IOWAD operator obtaining the induced generalized OWAD (IGOWAD) operator (also known as the Minkowski IOWAD). In this case we have also found a lot of particular cases including the Euclidean IOWAD operator.

The applicability of this new approach has been studied in a financial management problem regarding the assignment of financial products. We have seen that each aggregation operator may lead to different assignments since the results can be different. The use of OWAD and IOWAD operators permits to consider different degrees of optimism or pessimism in the analysis.

In future research, we expect to improve this current proposalby adding new characteristics in the problem such as the use of probabilistic information, norms, weighted averages and more complex structures.

\section{Acknowledgements}

We would like to thank the anonymous referees for valuable comments that have improved the quality of the paper.

\section{References}

Atanassov, K. 1986. Intuitionistic fuzzy sets, Fuzzy Sets and Systems 20(1): 87-96. http://dx.doi.org/10.1016/S0165-0114(86)80034-3

Beliakov, G.; Pradera, A.; Calvo, T. 2007. Aggregation functions: a guide for practitioners. Berlin: Springer-Verlag.

Belles-Sampera, J.; Merigó, J. M.; Guillén, M.; Santolino, M. 2013. The connection between distortion risk measures and ordered weighted averaging operators, Insurance: Mathematics and Economics 52(2): 411-420. http://dx.doi.org/10.1016/j.insmatheco.2013.02.008

Canós, L.; Liern, V. 2008. Soft computing-based aggregation methods for human resource management, European Journal of Operational Research 189(3): 669-681. http://dx.doi.org/10.1016/j.ejor.2006.01.054

Chen, H. Y.; Zhou, L. G. 2011. An approach to group decision making with interval fuzzy preference relations based on induced generalized continuous ordered weighted averaging operator, Expert Systems with Applications 38(10): 13432-13440. http://dx.doi.org/10.1016/j.eswa.2011.04.175 
Cheng, C. H.; Wang, J. W.; Wu, M. C. 2009. OWA-weighted based clustering method for classification problem, Expert Systems with Applications 36(3/1): 4988-4995.

http://dx.doi.org/10.1016/j.eswa.2008.06.013

De Luca, A.; Termini, S. 1972. A definition of a nonprobabilistic entropy in the setting on fuzzy sets theory, Information and Control 20(4): 301-312. http://dx.doi.org/10.1016/S0019-9958(72)90199-4

Dong, Y.; Xu, Y.; Li, H.; Feng, B. 2010. The OWA-based consensus operator under linguistic representation models using position indexes, European Journal of Operational Research 203(2): 455-463. http://dx.doi.org/10.1016/j.ejor.2009.08.013

Figueira, J.; Greco, S.; Ehrgott, M. 2005. Multiple criteria decision analysis: state of the art surveys. Boston: Springer. http://dx.doi.org/10.1007/b100605

Fodor, J.; Marichal, J. L.; Roubens, M. 1995. Characterization of the ordered weighted averaging operators, IEEE Transactions on Fuzzy Systems 3(2): 236-240. http://dx.doi.org/10.1109/91.388176

Gil-Aluja, J. 1999. Elements for a theory of decision in uncertainty. Dordrecht: Kluwer Academic Publishers. http://dx.doi.org/10.1007/978-1-4757-3011-1

Goldberger, J.; Tassa, T. 2008. A hierarchical clustering algorithm based on the Hungarian method, Pattern Recognition Letters 29(11): 1632-1638. http://dx.doi.org/10.1016/j.patrec.2008.04.003

Hamming, R. W. 1950. Error-detecting and error-correcting codes, Bell Systems Technical Journal 29(2): 147-160. http://dx.doi.org/10.1002/j.1538-7305.1950.tb00463.x

Han, Z.; Liu, P. D. 2011. A fuzzy multi-attribute decision-making method under risk with unknown attribute weights, Technological and Economic Development of Economy 17(2): 246-258. http://dx.doi.org/10.3846/20294913.2011.580575

Karayiannis, N. 2000. Soft learning vector quantization and clustering algorithms based on ordered weighted aggregation operators, IEEE Transactions on Neural Networks 11(5): 1093-1105. http://dx.doi.org/10.1109/72.870042

Kaufmann, A. 1975. Introduction to the theory of fuzzy subsets. New York: Academic Press.

Kuhn, H. W. 1955. The Hungarian method for the assignment problem, Naval Research Logistics Quarterly 2(1-2): 83-97. http://dx.doi.org/10.1002/nav.3800020109

Kuhn, H. W. 2012. A tale of three eras: the discovery and rediscovery of the Hungarian method, European Journal of Operational Research 219(3): 641-651. http://dx.doi.org/10.1016/j.ejor.2011.11.008

Lawler, E. L.; Wood, D. E. 1966. Branch-and-bound methods: a survey, Operations Research 14(4): 699-719. http://dx.doi.org/10.1287/opre.14.4.699

Merigó, J. M. 2013. The probabilistic weighted averaging distance and its application in group decision making, Kybernetes 42(5): 686-697. http://dx.doi.org/10.1108/K-06-2013-0107

Merigó, J. M.; Casanovas, M. 2011a. Decision making with distance measures and induced aggregation operators, Computers \& Industrial Engineering 60(1): 66-76.

http://dx.doi.org/10.1016/j.cie.2010.09.017

Merigó, J. M.; Casanovas, M. 2011b. Induced aggregation operators in the Euclidean distance and its application in financial decision making, Expert Systems with Applications 38(6): 7603-7608. http://dx.doi.org/10.1016/j.eswa.2010.12.103

Merigó, J. M.; Casanovas, M. 2011c. A new Minkowski distance based on induced aggregation operators, International Journal of Computational Intelligence Systems 4(2): 123-133. http://dx.doi.org/10.1080/18756891.2011.9727769.

Merigó, J. M.; Gil-Lafuente, A. M. 2009. The induced generalized OWA operator, Information Sciences 179(6): 729-741. http://dx.doi.org/10.1016/j.ins.2008.11.013

Merigó, J. M.; Gil-Lafuente, A. M. 2010. New decision making techniques and their application in the selection of financial products, Information Sciences 180(11): 2085-2094.

http://dx.doi.org/10.1016/j.ins.2010.01.028 
Merigó, J. M.; Gil-Lafuente, A. M. 2011. OWA operators in human resource management, Economic Computation and Economic Cybernetics Studies and Research 45(2): 153-168.

Merigó, J. M.; Gil-Lafuente, A. M.; Gil-Aluja, J. 2011a. Decision making with the induced generalized adequacy coefficient, Applied and Computational Mathematics 10(2): 321-339.

Merigó, J. M.; Gil-Lafuente, A. M.; Gil-Aluja, J. 2011b. A new aggregation method for strategic decision making and its application in assignment theory, African Journal of Business Management 5(11): 4033-4043.

Merigó, J. M.; Wei, G. W. 2011. Probabilistic aggregation operators and their application in uncertain multi-person decision making, Technological and Economic Development of Economy 17(2): 335-351. http://dx.doi.org/10.3846/20294913.2011.584961

Merigó, J. M.; Xu, Y. J.; Zeng, S. Z. 2013. Group decision making with distance measures and probabilistic information, Knowledge-Based Systems 40(1): 81-87.

http://dx.doi.org/10.1016/j.knosys.2012.11.014

Merigó, J. M.; Yager, R. R. 2013. Generalized moving averages, distance measures and OWA operators, International Journal of Uncertainty, Fuzziness and Knowledge-Based Systems 21(4): 533-559. http://dx.doi.org/10.1142/S0218488513500268

Szmidt, E.; Kacprzyk, J. 2000. Distances between intuitionistic fuzzy sets, Fuzzy Sets and Systems 114(3): 505-518. http://dx.doi.org/10.1016/S0165-0114(98)00244-9

Vizuete-Luciano, E.; Gil-Lafuente, A. M.; García-González, A.; Boria-Reverter, S. 2013. Forgotten effects of corporate social and environmental responsibility: a case study of Catalonian economy, Kybernetes 42(5): 736-753. http://dx.doi.org/10.1108/K-04-2013-0065

Wei, G. W.; Zhao, X.; Lin, R. 2010. Some induced aggregating operators with fuzzy number intuitionistic fuzzy information and their applications to group decision making, International Journal of Computational Intelligence Systems 3(1): 84-95. http://dx.doi.org/10.1080/18756891.2010.9727679

Wei, G. W.; Zhao, X.; Wang, H. 2012. An approach to multiple attribute group decision making with interval intuitionistic trapezoidal fuzzy information, Technological and Economic Development of Economy 18(2): 317-330. http://dx.doi.org/10.3846/20294913.2012.676995

Xu, Z. S.; Chen, J. 2008a. Ordered weighted distance measure, Journal Systems Sciences Systems Engineering 17(4): 432-445. http://dx.doi.org/10.1007/s11518-008-5084-8

$\mathrm{Xu}, \mathrm{Z}$. S.; Chen, J. 2008b. Some models for deriving the priority weights form interval fuzzy preference relations, European Journal of Operational Research 184(1): 266-280. http://dx.doi.org/10.1016/j.ejor.2006.11.011

Xu, Z. S.; Da, Q. L. 2003. An overview of operators for aggregating information, International Journal of Intelligent Systems 18(9): 953-969. http://dx.doi.org/10.1002/int.10127

$\mathrm{Xu}, \mathrm{Z}$. S; Xia, M. 2011. Induced generalized intuitionistic fuzzy operators, Knowledge-Based Systems 24(2): 197-209. http://dx.doi.org/10.1016/j.knosys.2010.04.010

Yager, R. R. 1988. On ordered weighted averaging aggregation operators in multi-criteria decision making, IEEE Transactions on Systems, Man and Cybernetics 18(1): 183-190. http://dx.doi.org/10.1109/21.87068

Yager, R. R. 1993. Families of OWA operators, Fuzzy Sets and Systems 59(2): 125-148. http://dx.doi.org/10.1016/0165-0114(93)90194-M

Yager, R. R. 2002. Heavy OWA operators, Fuzzy Optimization and Decision Making 1(4): 379-397. http://dx.doi.org/10.1023/A:1020959313432

Yager, R. R. 2003. Induced aggregation operators, Fuzzy Sets and Systems 137(1): 59-69. http://dx.doi.org/S0165-0114(02)00432-3

Yager, R. R.; Filev, D. P. 1999. Induced ordered weighted averaging operators, IEEE Transactions on Systems, Man and Cybernetics B 29(2): 141-150. http://dx.doi.org/10.1109/3477.752789 
Yager, R. R.; Kacprzyk, J. 1997. The ordered weighted averaging operators: theory and applications. Norwell, MA: Kluwer Academic Publishers. http://dx.doi.org/10.1007/978-1-4615-6123-1

Yager, R. R.; Kacprzyk, J.; Beliakov, G. 2011. Recent developments on the ordered weighted averaging operators: theory and practice. Berlin: Springer-Verlag. http://dx.doi.org/10.1007/978-3-642-17910-5

Zeng, S. Z.; Merigó, J. M.; Su, W. H. 2013. The uncertain probabilistic OWA distance operator and its application in group decision making, Applied Mathematical Modelling 37(9): 6266-6275. http://dx.doi.org/10.1016/j.apm.2013.01.022

Zeng, S. Z.; Su, W. 2011. Intuitionistic fuzzy ordered weighted distance operator, Knowledge-Based Systems 24(8): 1224-1232. http://dx.doi.org/10.1016/j.knosys.2011.05.013

Emili VIZUETE-LUCIANO is Professor of Economics and Business Administration at the University of Barcelona, Spain. He is a $\mathrm{PhD}$ candidate in Business Administration. He has published several articles in journals, books and conference proceedings including journals such as Universia Business Review and Kybernetes. He has participated in several scientific committees and serves as a reviewer in a wide range of journals including the European Journal of Operational Research, Computational and Mathematical Organization Theory, Mathematical and Computer Modelling. He is a member of the Board Committee of AMSE Organization. He is currently interested in Decision Making, Finance, Marketing and Uncertainty.

José M. MERIGÓ has a MSc and a PhD degree in Business Administration from University of Barcelona, Spain. His PhD received the Extraordinary Award from the University of Barcelona. He also holds a Bachelor Degree in Economics and a Master Degree in European Business Administration and Business Law from Lund University, Sweden. He is an Assistant Professor in the Department of Business Administration at the University of Barcelona. He has published more than 150 papers in journals, books and conference proceedings including journals such as Information Sciences, International Journal of Information Technology and Decision Making, Technological and Economic Development of Economy, Expert Systems with Applications, International Journal of Intelligent Systems, International Journal of Uncertainty, Fuzziness and Knowledge-Based Systems, Cybernetics \& Systems, Computers \& Industrial Engineering and International Journal of Fuzzy Systems. He is on the editorial board of several journals, participates in several scientific committees and serves as a reviewer in a wide range of journals. He is currently interested in Aggregation Operators, Decision Making and Uncertainty.

Anna M. GIL-LAFUENTE is an Associate Professor at the University of Barcelona. She holds a Master and a $\mathrm{PhD}$ degree in Business Administration from the University of Barcelona. She has published more than 200 publications in journals, books and conference proceedings, including journals such as Information Sciences, Expert Systems with Applications, International Journal of Uncertainty, Fuzziness and Knowledge-Based Systems, African Journal of Business Management and Economic Computation and Economic Cybernetics Studies and Research. She has also published several books including two in the Book Series of Springer "Studies in Fuzziness and Soft Computing" and one with World Scientific. She is co-editor in chief of the 8 international journals that publishes the AMSE organization. She has participated in a wide range of scientific committees and as a reviewer in international journals. She is currently interested in Decision Making, Finance and Uncertainty.

Sefa BORIA-REVERTER is Associate Professor of Economics and Business Administration at the University of Barcelona, Spain. She is a PhD candidate in Business Administration. She has published several in journals, books and conference proceedings including journals such as Universia Business Review and Kybernetes. She has participated in several scientific committees and serves as a reviewer in Universia Business Review. She is currently interested in Organization, Corporate Social Responsibility and Decision Making. 